Original Research

\title{
Sociodemographic Variables and History of Trauma and Disease Influence Consciousness after Hypnotic Induction
}

Antonella Ciaramella, MD ${ }^{1,2, *}$

1. Aplysia onlus, partner in an education programme of the University of Pisa, Florence, Padua and MIUR, Italy; E-Mail: ciarantogift@gmail.com

2. Psychosomatic Center, GIFT institute of Integrative Medicine, Pisa, Italy

* Correspondence: Antonella Ciaramella; E-Mail: ciarantogift@gmail.com

Academic Editor: Giuseppe De Benedittis

Special Issue: Hypnosis: from Neural Mechanisms to Clinical Practice

OBM Integrative and Complementary Medicine

2020, volume 5, issue 1

doi:10.21926/obm.icm.2001014
Received: January 01, 2020

Accepted: March 09, 2020

Published: March 17, 2020

\begin{abstract}
Over the last 30 years, several neuroimaging and neurophysiological experiments have lent support to the neuropsychology of consciousness, and several definitions have followed to describe it. The phenomenological perspective of consciousness facilitates the description of the individual's awareness experience of internal states (e.g., perception, sensations, emotion, volition, or memories), thus helping us to better understand the relationship between the brain and mind. Although significant research has been aimed at evaluating the neurobiological aspects underlying the phenomenon of consciousness, there is a lack of information regarding the effect of clinical and sociodemographic factors on the modification of the altered state of consciousness in hypnosis. Therefore, the main objective of this study was to investigate how the variables of demographic and clinical history affected the alteration of consciousness during hypnotic induction. Consciousness was investigated within a single session using the $\mathrm{PCl}$ (Phenomenology of Consciousness Inventory) Italian translation, during the administration of the hypnotic susceptibility scale HGSHS:A (Harvard Group Scale of Hypnotic Susceptibility, Form A) Italian translation. Three hundred and fortynine subjects from the general population (aged 19-72 years; 112 male and 237 female)
\end{abstract}

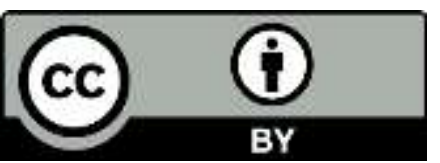

(C) 2020 by the author. This is an open access article distributed under the conditions of the Creative Commons by Attribution License, which permits unrestricted use, distribution, and reproduction in any medium or format, provided the original work is correctly cited. 
were investigated in a single session. Twenty-six subjects (7.4\%) reported a history of recent psychological trauma, $6.6 \%$ reported a history of substance misuse, $7.7 \%$ had a history of psychiatric disorder, and $9.7 \%$ had a history of medical disease. Age was observed to be a negative predictor of hypnoidal state, intended to be a general measure of trance $(\beta=-0.12$; $p=0.01)$. However, age also contributed to changing the phenomenology of consciousness, predicting greater vividness of imagery, reduction in time sense, fear, arousal, anger, negative affect, and perception. Females were more hypnotizable than males $(\beta=0.18 ; p=0.000)$, with a reduced memory of suggestions, and an increase in the altered state. Subjects with perceived psychological trauma were more prone to have reduced memory of suggestions $(\beta=0.14 ; p=0.01)$. A hypnotic state is the result of a combination of several individual predisposing traits and variables that are contextual to a specific situation. Age, gender, and perceived psychological trauma play a critical role in the hypnotic state, making the experience more subjective and influencing the quality of sensation, emotion, volition, and thought (consciousness phenomenology), which are fundamental for an appropriate response to suggestions.

\section{Keywords}

Consciousness; hypnosis; trauma; illness; gender; age

\section{Background}

While consciousness is often investigated in several fields, its meaning is still unclear. The word 'consciousness' refers to the state of understanding or realizing something, the state of being awake, or acknowledging the existence of something. Vithoulkas and Muresanu [1] have described consciousness as a function of the human mind that processes information by storing or rejecting it through perception (via the five senses), reasoning, imagination, emotion, and memory. Likewise, we consider awareness (including self-awareness) (the content) and wakefulness (the state) to be the two main components of consciousness and an altered state of consciousness as the product of any condition that changes the ordinary waking consciousness.

Over the last 30 years, several neuroimaging and neurophysiological experiments have lent support to the neuropsychology of consciousness, suggesting that a phenomenological perspective of consciousness enables us to explain the individual's awareness experience of internal states (e.g., perception, sensations, emotion, volition, or memories) [2, 3]. This perspective helps us to better understand the relationship between the brain and mind.

Brown and Fromm [4] proposed that hypnosis comprises three principal aspects: altered states of consciousness, expectation and suggestibility, and the hypnotic relationship. Extending the neurophysiological and phenomenological research into the field of hypnosis, Holroyd hypothesized that imagination/susceptibility and an altered state of consciousness, combined with expectancy, may account for how individuals experience hypnotism [4, 5]. According to Weitzenhoffer [6], "the term hypnosis is reserved for the state, and the term of hypnotism for the production, study, and use of suggestion, with the state of hypnosis presumably being present whether or not it adds anything tangible to the situation". 
On the one hand, susceptibility represents the individual's physiological ability to respond to suggestion with non-voluntary behavior; on the other, the therapeutic action of hypnosis depends on the individual's subjective ability to enter an altered state of consciousness, decreasing sensibility, and responsiveness to external stimuli, "shifting from voluntary to automatic activity (trance)" [7]. Although there have been several studies on hypnosis and the ease of entering into a trance depending on the susceptibility levels, there is scarce literature investigating whether and how demographic and clinical variables can affect the change in consciousness experienced during hypnotism. Studies specifically analyzing the age- or gender-related differences in the alteration of the state of consciousness after hypnotic induction are particularly rare. However, data can often be indirectly extrapolated from reports on the validation of hypnotic scales [8] or assessment of the clinical outcomes of hypnotic treatment [9], which have provided some evidence that there are differences in hypnosis based on gender or age. For example, although hypnosis has been reported to be more successful in female subjects when used for quitting smoking, there is no mention as to how the phenomenology of consciousness varies between the two sexes [10].

Nevertheless, the latest studies do indicate that gender influences cognitive functions such as perception, emotion, and memory [11], and that sex hormones can predict the recovery of consciousness after severe traumatic brain injury [12].

Brain imaging studies highlight specific patterns of activation of the brain structure during hypnosis-related modification of consciousness. Two of the principal methods of hypnosis, relaxation, and mental absorption, which are included in a standard hypnotic induction as well as the Stanford Hypnotic Susceptibility Scale A (SHSS:A), are modulated in an opposite manner by the same brain structure [13]. An example for this is the rostral or posterior part of the anterior cingulate cortex (ACC). This suggests different involvement of attention, cortical arousal, and selfregulation, depending on the type of hypnotic method [13]. Furthermore, a negative correlation has been observed between the self-rated score of relaxation and the activities of the mesencephalic tegmentum, brainstem area, and the thalamus, determined using positron emission tomography (PET) of the regional cerebral blood flow (rCBF). An increase in mental absorption is rather correlated with increased activity in the thalamus and upper pons [13].

Differences in the involvement of the same structures alter the phenomenological experience that characterizes the hypnotic state. Therefore, despite neurobiological research that reveals how changes in the activity of brain structures are essential for the basic regulation of the state of consciousness in hypnosis, little clinical research has investigated how clinical factors such as traumatic experiences or the presence of illness may actually influence the phenomenology of consciousness in hypnosis.

Some researchers have investigated the relationship between life-threatening events and the modification of consciousness [14, 15]. Trauma-related altered state of consciousness (TRASC) is characterized by an alteration in the sense of time (reliving the trauma as flashback), thought (negative self-referential cognition), body (depersonalization and hyperarousal), and emotion (severe emotion numbing, sadness, anger, and shame) [14], suggesting that trauma may play a role in the alteration of consciousness. Together, this evidence is fundamental, as these factors may change the phenomenology of consciousness as a response to hypnotic induction. In particular, an alteration in the autobiographical memory has been observed in subjects with an increased number of stressful life events, alongside a positive correlation with increased scores for some dimensions of somatization and on the SGSS:A [15]. 


\subsection{Aim}

This study aimed to evaluate how certain dimensions such as age and sex, the perception of having recently experienced psychological trauma, and the presence of medical or psychiatric disorders can influence the alteration of consciousness during hypnotic induction, in a non-clinical population.

\section{Method}

\subsection{Study Design}

This was a retrospective observational study investigating the modification of consciousness during the induction of hypnosis, based on sociodemographic and medical variables in a group from the general population that was enrolled in a university setting from 2017 to 2018. Consciousness was investigated during a single session using the $\mathrm{PCl}$ (Phenomenology of Consciousness Inventory) [16]. Italian translation [17], after the administration of the hypnotic susceptibility scale HGSHS:A (Harvard Group Scale of Hypnotic Susceptibility, Form A) [18] Italian translation [19].

\subsection{Samples and Setting}

The enrolled subjects responded to an announcement (including our contact information) displayed at several sites at the University of Pisa, as well as the University website. Groups of 1020 subjects were recruited for each session. The sessions were conducted at the GIFT Institute of Integrative Medicine in Pisa, Italy. This research was conducted in accordance with the ethical principles of the Declaration of Helsinki for medical research involving human subjects, and the anonymity of the participants was protected. All the subjects signed informed consent that contained clear and explicit information regarding data publication.

\subsection{Assessment}

\subsubsection{CRF}

The Case Report Form (CRF) was used to obtain information from the subjects regarding their gender, age, marital status (single, married, divorced, widowed), education (sum of total years starting from the first year of primary school), and income (low, medium, high). History of medical disease (MD), psychiatric disorders (PD), substance misuse (SM), and recent psychological traumas (T) were assessed using code 1 for yes and 2 for no. All the clinical dimensions were investigated using the following questions:
A: Over the last year, have you been affected by some physical disease?
B: Over the last year, have you been affected by some psychiatric disorder?
C: Over the last year, have you been affected by substance misuse?
D: Over the last year, have you been affected by any psychological trauma? 


\subsubsection{PCI}

An interesting instrument for assessing several dimensions of consciousness, linked to subjective experience associated with hypnosis, is the self-reported measure "Phenomenology of Consciousness Inventory (PCI)" [16]. This instrument takes into account the relevance of the widely known susceptibility assessments, the Stanford C scale [20] and the Harvard Group Scale (HGSHS) [18], with which it is strongly correlated (validity coefficient 0.86) [21]. Unlike other scales that provide a measure of susceptibility, the PCI includes the predictor of HGS score (pHGS), described as the hypnoidal state or "depth of trance score", which is "a phenomenology-based measure of trance that is primarily a function of the state effects, although influenced by trait factors" [17, 22].

Wagstaff and colleagues suggested that subjects in the hypnoidal state were "less prone to distortion from response sets and demand characteristics" [23]. If hypnotizability is "an individual's ability to experience the suggested alteration in physiology, sensation, emotion, thoughts, or behavior during hypnosis [24]", the "hypnoidal state is a general measure of trance" [17]. In line with Kumar et al. [25], some trait factors (absorption-permissiveness, general sensation-seeking, and social desirability) and state factors (dissociated control state, positive effect, negative effect, attention to internal processes, and visual imagery) included in the $\mathrm{PCl}$ assessment predict hypnotizability in $9 \%$ and $22 \%$, respectively.

The phenomenological nature of $\mathrm{PCl}$ means that, unlike the HGSHS:A, it does not measure "hypnotic susceptibility" (a trait), but rather "hypnotic responsivity". Hypnotic responsivity is assumed to be a "state measure" of hypnotic skill in a particular moment. The $\mathrm{PCl}$ is an inventory that includes 53 items in a 0-6-scale response [17]. The parameters of $\mathrm{PCl}$ are joy, sexual excitement, love, anger, sadness, fear, body image, time sense, perception, meaning, amount of imagery, vividness of imagery, direction of attention, absorption, self-awareness, altered state, internal dialogue, rationality, volitional control, memory, arousal, positive affect, negative affect, altered experience, imagery, and attention. It includes the hypnoidal state score (HSS), which is a unit score correlated with the degree of hypnotizability, thereby contributing to our understanding of a subject's ability to develop a hypnotic condition. Through the above dimensions, the PCl allows us to categorize subjects into nine hypnotic types, corresponding to the characteristics of the subject's phenomenological trance. These dimensions could be extremely useful in the clinical setting, providing an indication to the hypnotist as to what kind of suggestions to use.

Furthermore, by applying cluster analysis to the group of subjects with low susceptibility to HGSHS (scores of 0-2), use of the subjective experience assessed by the $\mathrm{PCl}$ indicated a subgroup of subjects (pseudo-lows), that reported moderate drops in self-awareness, rationality, volition control, and memory, that were moderately hypnotizable [26]. Subjects were asked to complete the $\mathrm{PCl}$ according to the hypnotic assessment procedure (PCI-HAP) devised by Pekala et al. [26]. After introducing the suggestion of eye catalepsy, and before the post-hypnotic SHSS:A suggestion, the hypnotist told the subjects to stay silent and "just continue to experience the state you are in right now" for two minutes. The subjects were then requested to refer to these two minutes to respond to the $\mathrm{PCl}$ questionnaire. Usually, administration of the $\mathrm{PCl}$ is preceded by the induction procedure of a "body scan" and "mind calm". However, due to the limited previous experience in administration of the $\mathrm{PCl}$, it was preferred to follow it precisely, in order to rely on a validated scale for hypnotic induction. This version of PCI had already been translated into Italian [17]. 


\subsubsection{HGSHS}

Shor and Orne's [18] construction of the Harvard Group Scale of Hypnotic Susceptibility: Form A (HGSHS:A) is a group version of Weitzenhoffer and Hilgard's Stanford Hypnotic Susceptibility Scale: Form A (SHSS:A) [27]. This scale involves a standard hypnotic procedure with 12 standard suggestions: head falling, eye closure, hand lowering, arm immobilization, finger lock, arm rigidity, hand moving, communication inhibition, hallucination, eye catalepsy, post-hypnotic suggestion, and amnesia. Each suggestion provides a dichotomous response (positive or negative). This hypnotic scale is cost-effective, being a self-reported measure for simultaneously testing groups of people. We used the validated Italian translation, which has a Kuder-Richardson coefficient of 0.70, making it comparable to the other European samples [19].

\subsection{Statistical Analysis}

Data were analyzed using the statistical software SPSS version 21 (IBM). After the application of the Kolmogorov-Smirnov test that gives information on the Gaussian distribution of the data, the $t$ test and Pearson's correlation analysis were performed. Non-parametric analyses (Mann-Whitney $U, \chi$-square, and Fisher's exact test) were used when the number of subjects was lower than five, and for categorical variables. To assess the sociodemographic predictors of variation in hypnotic phenomenology, we used linear regression analysis, taking the $\mathrm{PCl}$ dimensions as dependent variables, while age, gender, education, social and marital status, history of medical disease, psychiatric disorders, substance misuse, and trauma were considered as the independent variables. All the regression models were corrected for age and gender. Statistical significance was set at $p<0.05$.

\section{Results}

\subsection{Sample Description}

Three hundred and forty-nine subjects from the general population (aged 19-72 years; 112 male and 237 female) were investigated during a single session. Twenty-six subjects (7.4\%) reported a history of perceived-psychological trauma (T), 22 (6.6\%) reported a history of substance misuse (SM), 27 (7.7\%) had a history of psychiatric disorder (PD), and 34 subjects (9.7\%) had a medical disease (MD) during the previous year (Table 1).

Subjects with a history of MD were older than those without it (n.1), and there was a higher prevalence of married subjects (n.2). However, there were no differences in the prevalence of MD based on education or income. Regarding PD, subjects with PD were older (n.3) and showed a higher prevalence of divorce (n.4) compared to subjects without a history of PD. No differences were observed in terms of education, gender, or income. In the case of SM, no differences were observed in the prevalence of SM, irrespective of the age, education, gender, and income of subjects. Subjects with recent trauma were older (n.5) than those without, and showed an increased prevalence of divorce $\left(\chi^{2}=40.89 ; p<0.0001\right)$ (n.6). No differences in the prevalence of trauma were observed irrespective of the gender, education, or income (Table 1). 
Table 1 Sample description.

\begin{tabular}{|c|c|c|c|c|c|c|c|c|}
\hline & \multicolumn{2}{|c|}{$\begin{array}{l}\text { MD } \\
{[n . / x M(s D]}\end{array}$} & \multicolumn{2}{|c|}{$\begin{array}{l}\text { PD } \\
{[n . / x M(s D]}\end{array}$} & \multicolumn{2}{|c|}{$\begin{array}{l}\text { SM } \\
{[n . / x M(s D]}\end{array}$} & \multicolumn{2}{|c|}{$\begin{array}{l}\text { T } \\
{[\text { n./xM (sD] }}\end{array}$} \\
\hline & $\begin{array}{l}\text { Yes } \\
\text { (n. 34) }\end{array}$ & $\begin{array}{l}\text { No } \\
\text { (n. 315) }\end{array}$ & $\begin{array}{l}\text { Yes } \\
\text { (n. 27) }\end{array}$ & $\begin{array}{l}\text { No } \\
\text { (n. 322) }\end{array}$ & $\begin{array}{l}\text { Yes } \\
\text { (n. 22) }\end{array}$ & $\begin{array}{l}\text { No } \\
\text { (n. 327) }\end{array}$ & $\begin{array}{l}\text { Yes } \\
\text { (n. 26) }\end{array}$ & $\begin{array}{l}\text { No } \\
\text { (n. 323) }\end{array}$ \\
\hline Age & $\begin{array}{l}40.24 \\
(15.45)^{1}\end{array}$ & $\begin{array}{l}28.2 \\
(9.78)\end{array}$ & $\begin{array}{l}42.85 \\
(14.73)^{3}\end{array}$ & $\begin{array}{l}28.03 \\
(9.91)\end{array}$ & $\begin{array}{l}26.73 \\
(11.04)\end{array}$ & $\begin{array}{l}29.48 \\
(11.17)\end{array}$ & $\begin{array}{l}37.62 \\
(15.58)^{5}\end{array}$ & $\begin{array}{l}28.39 \\
(10.24)\end{array}$ \\
\hline $\begin{array}{l}\text { Education } \\
\text { (n. years) }\end{array}$ & $\begin{array}{l}16.06 \\
(3.52)\end{array}$ & $\begin{array}{l}16.92 \\
(2.75)\end{array}$ & $\begin{array}{l}17 \\
(2.68)\end{array}$ & $\begin{array}{l}16.79 \\
(2.87)\end{array}$ & $\begin{array}{l}16.27 \\
(2.64)\end{array}$ & $\begin{array}{l}16.85 \\
(2.87)\end{array}$ & $\begin{array}{l}16.36 \\
(3.20)\end{array}$ & $\begin{array}{l}16.84 \\
(2.82)\end{array}$ \\
\hline Males & 7 & 105 & 8 & 104 & 8 & 104 & 7 & 105 \\
\hline Females & 27 & 264 & 19 & 218 & 14 & 223 & 19 & 218 \\
\hline \multicolumn{9}{|l|}{ Civil status } \\
\hline Single & 17 & 259 & 14 & 261 & 20 & 256 & 16 & 260 \\
\hline Married & 15 & 36 & 11 & 40 & 2 & 49 & 6 & 45 \\
\hline Divorced & 1 & 13 & 2 & 12 & 0 & 14 & 3 & 11 \\
\hline Widowed & $1^{2}$ & 3 & $0^{4}$ & 4 & 0 & 4 & $1^{6}$ & 3 \\
\hline \multicolumn{9}{|l|}{ Income } \\
\hline Low & 2 & 34 & 2 & 34 & 3 & 33 & 3 & 33 \\
\hline Medium & 30 & 263 & 22 & 271 & 19 & 274 & 21 & 272 \\
\hline High & 2 & 18 & 3 & 17 & 0 & 20 & 2 & 18 \\
\hline
\end{tabular}

MD: medical disease; PD: psychiatric disorder; SM: substance misuse; T: psychological trauma, Harvard Group Scale of Hypnotic Susceptibility: Form A (HGSHS:A); hypnoidal state score (HSS). 1: unpaired t-test: $t=6.38 ; p=0.000 ; 2$ : chi-squared analysis ( 4 missing values) $\chi 2=35.90, p=$ $0.000 ; 3$ : unpaired $t$-test: $t=7.08 ; p=0.000 ; 4$ : chi-squared analysis $\chi 2=21.96, p=0.000 ; 5$ : unpaired t-test: $t=4.17 ; p=0.000 ; 5$ : chi-squared analysis $\chi 2=31.47, p=0.000$. The numbers given in superscript are described in the text.

\subsection{Susceptibility, Hypnoidal State, Clinical, and Sociodemographic Variables}

Although age was not correlated with the total HGSHS:A score, a negative correlation was observed between age and the hypnoidal state $(r=-0.13, p=0.013)$. Using HGSHS:A and HSS scores as dependent variables and age as the independent variable, we demonstrated that age was a negative predictor of HSS (Figure 1).

No differences were observed between genders in terms of hypnoidal state score. However, there were differences in hypnotic susceptibility between the genders. Specifically, females showed higher HGHS:A total scores than males ( $x M=6.30, s D=2.69$ for females and $x M=5.09$, $s D=2.53$ for males; $t=3.79, p=0.0001$ ). Gender (female) was a positive predictor of a high degree of susceptibility but not of degree of HSS (Table 2). Gender also remained a predictor of susceptibility 
when age was included in the model (Table 2). No other differences in either hypnotic susceptibility or hypnoidal state were found when the sample was sub-divided by the other sociodemographic variables.

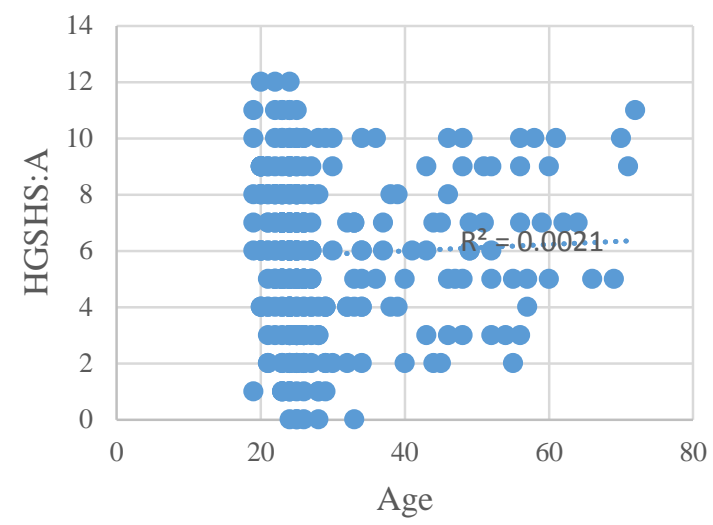

A

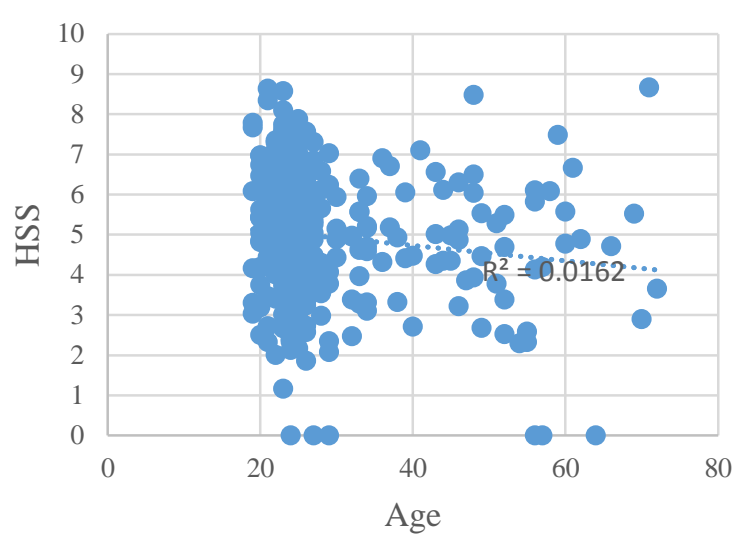

B

Figure 1 Linear regression analysis of A: Group Scale of Hypnotic Susceptibility: Form A (HGSHS: $A)$ total score and age $(B=.01 ; \beta=.46 ; p=.39)$ and $B$ : Hypnoidal State Score (HSS) and age $(B=-.19 ; \beta=-.12 ; p=.017)$.

Table 2 Gender as a predictor of total susceptibility score.

\begin{tabular}{llllllll}
\hline & B & S.D. & $\boldsymbol{\beta}$ & $\mathbf{t}$ & Sig. & \multicolumn{2}{l}{$\begin{array}{l}\text { 95\%Cl for Exp (B) } \\
\text { Inf. Sup. }\end{array}$} \\
\hline Gender & & & & & & & \\
HGSHS:A & 1.06 & .30 & .18 & 3.51 & .000 & .46 & 1.65 \\
$*$ age & 1.05 & .30 & .18 & 3.50 & .001 & .46 & 1.65 \\
\hline
\end{tabular}

Harvard Group Scale of Hypnotic Susceptibility: Form A (HGSHS:A); Linear Regression Analysis;

* inclusion of age in the model.

\subsection{Relationship between Sociodemographic Variables and Phenomenology of Consciousness}

As mentioned earlier, age appeared to be relevant and negatively correlated with the depth of trance, i.e., the modification of consciousness during hypnotic induction. When the phenomenology of trance in subjects above 30 years of age was compared to those below this age , some differences were observed in the mean age scoring (Figure 2). Specifically, subjects older than 30 years had lesser sexual excitement, fear, internal dialogue, and arousal, but greater vividness of imagery, self-awareness, and rationality (Figure 2). As shown in Table 3, age was a predictor of several phenomena of consciousness, thereby modifying the phenomenology of hypnosis. On one hand, age increases the hypnotic state, predicting greater vividness of imagery and reduced time sense, fear, arousal, anger, negative effect, and perception (the perception of space relative to the environment where the subject is located). On the other, it contributes to a reduction in the depth of trance, negatively predicting sexual excitement, amount of imagery, altered state, altered experience, and internal dialogue, and positively predicting rationality. 
Higher age predicted greater $\mathrm{PCl}$ reliability index score (Table 3).

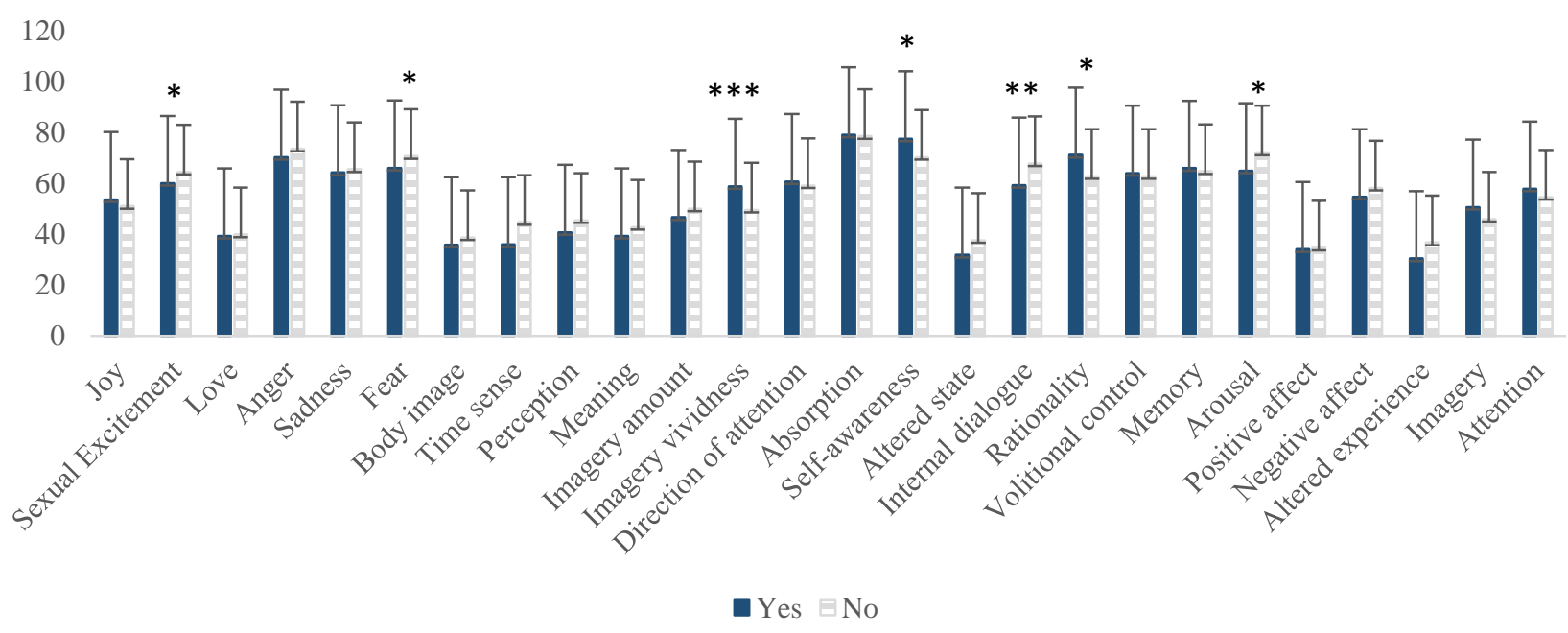

Figure 2 Difference between age groups (yes $=\geq 30$; no $<30$ ) in consciousness phenomenology $(\mathrm{PCl})$ during hypnotic induction using the HGSHS:A. T-test for unpaired data analysis. ${ }^{*} p<0.05 ;{ }^{* *} p<0.01 ; * * * p<0.001 ; * * * * p<0.0001$.

Table 3 Age as a predictor of hypnotic consciousness phenomenology.

\begin{tabular}{|c|c|c|c|c|c|c|c|}
\hline & B & S.D. & $\beta$ & $\mathbf{t}$ & Sig. & \multicolumn{2}{|c|}{$\begin{array}{l}95 \% \mathrm{Cl} \text { for } \operatorname{Exp}(\mathrm{B}) \\
\text { Inf. Sup. }\end{array}$} \\
\hline \multicolumn{8}{|l|}{ Age } \\
\hline Sexual Excitement ${ }^{a}$ & -.25 & .06 & -.19 & -3.77 & .000 & -.38 & -.12 \\
\hline Anger ${ }^{a}$ & -.25 & .06 & -.19 & -3.68 & .000 & -.38 & -.11 \\
\hline Fear $^{a}$ & -.26 & .08 & -.17 & -3.33 & .001 & -.42 & -.10 \\
\hline Time sense ${ }^{a}$ & -.46 & .15 & -.16 & -3.02 & .003 & -.76 & -.16 \\
\hline Perception $^{a}$ & -.35 & .13 & -.13 & -2.62 & .009 & -.62 & -.08 \\
\hline Imagery amount ${ }^{a}$ & -.23 & .11 &.-10 & -1.98 & .048 & -.46 & -.002 \\
\hline Imagery vividness ${ }^{a}$ & .28 & .10 & .14 & 2.71 & 0.007 & .07 & .49 \\
\hline Altered state $^{a}$ & -.32 & .13 & -.12 & -2.40 & .017 & -.58 & -.05 \\
\hline Internal dialogue ${ }^{a}$ & -.47 & .12 & -.20 & -3.93 & .000 & -.70 & -.23 \\
\hline Rationality $^{a}$ & .35 & .12 & .15 & 2.90 & .004 & .11 & .59 \\
\hline Arousal $^{a}$ & -.34 & .11 & -.15 & -2.97 & .003 & -.56 & -.11 \\
\hline Negative affect ${ }^{a}$ & -.26 & .10 & -.12 & -2.41 & .016 & -.47 & -.049 \\
\hline Altered experience ${ }^{a}$ & -.33 & .14 & -.12 & -2.32 & .021 & -.61 & -.05 \\
\hline Reliability index score ${ }^{a}$ & .01 & .003 & .21 & 4.17 & .000 & .00 & .01 \\
\hline
\end{tabular}

Linear Regression Analysis. a: including gender in the model, the statistical significance does not change. 
As shown in Figure 3, we observed statistically significant differences between genders in several $\mathrm{PCl}$ parameters. Specifically, males showed greater sexual excitement, internal dialogue, memory, and positive affect than females. By assigning males with a code of 1 and females as 2 , linear regression revealed that gender was a negative predictor of sexual excitement, positive affect, memory, and internal dialogue. As women were assigned with a higher code than males, one could argue that female sex was a negative predictor of these parameters of the $\mathrm{PCl}$, although it also appeared that the female gender was a positive predictor of the altered state of consciousness (Table 4). Adding age to the model had no effect on the statistical significance of the observed values.

No relationship was observed between marital status and hypnotizability. However, this sociodemographic variable did affect several dimensions of consciousness, when taken individually. There were no changes to the predictive ability of the phenomenology of trance when gender was added to the linear regression model, but this was totally annulled when age was added to the model (Table 4).

Education also affected the profile of trance, and was observed to be a negative predictor of positive effect and the reliability index score. For both of these variables, the statistical significance of the regression analysis did not change when age and gender were added to the model. Based on this analysis, income did not represent a predictor of trance phenomenology.

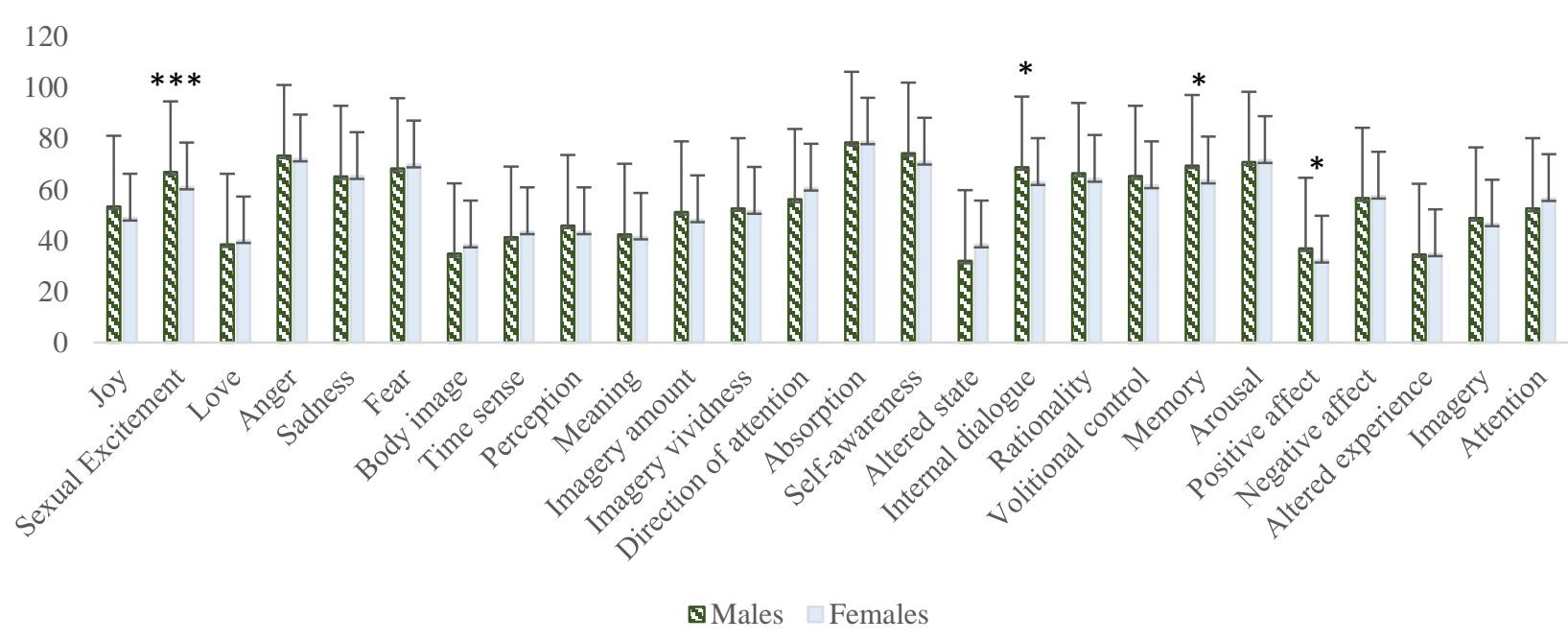

Figure 3 Differences between genders in consciousness phenomenology $(\mathrm{PCl})$ during hypnotic induction using the HGSHS:A. T-test for unpaired data analysis. ${ }^{*} p<0.05$; ${ }^{* *} \mathrm{p}<0.01 ;{ }^{* * *} \mathrm{p}<0.001 ; * * * * \mathrm{p}<0.0001$. 
Table 4 Gender and sociodemographic parameters are predictors of phenomenology of consciousness after hypnosis induction.

\begin{tabular}{|c|c|c|c|c|c|c|c|}
\hline \multirow{2}{*}{ Gender } & \multirow[t]{2}{*}{ B } & \multirow[t]{2}{*}{ S.D } & \multirow[t]{2}{*}{$\beta$} & \multirow[t]{2}{*}{$\mathbf{t}$} & \multirow[t]{2}{*}{ Sig. } & \multicolumn{2}{|c|}{$\begin{array}{l}95 \% \mathrm{Cl} \text { for } \operatorname{Exp}(\mathrm{B}) \\
\text { Inf. Sup. }\end{array}$} \\
\hline & & & & & & & \\
\hline Sexual Excitement & -5.78 & 1.52 & -.20 & -3.80 & .000 & -8.78 & -2.74 \\
\hline Altered state & 6.28 & 3.06 & .10 & 2.04 & .041 & .25 & 12.31 \\
\hline Positive affect & -4.56 & 2.04 & -.11 & -2.23 & .03 & -8.58 & -.54 \\
\hline Memory & -5.86 & 2.86 & -.10 & -2.04 & .041 & -11.48 & -.23 \\
\hline Internal Dialogue & -5.84 & 2.78 & -.11 & -2.10 & .036 & -11.30 & -.37 \\
\hline \multicolumn{8}{|l|}{ Education } \\
\hline Positive affect & -.94 & .35 & -.14 & -2.68 & .008 & -1.63 & -.25 \\
\hline Reliability index score & -.03 & .01 & -.16 & -3.12 & .002 & -.05 & -.01 \\
\hline \multicolumn{8}{|l|}{ Civil Status } \\
\hline Sexual excitement ${ }^{a . b}$ & -4.47 & 1.68 & -.14 & -2.65 & .008 & -7.80 & -1.15 \\
\hline Fear ${ }^{a . b}$ & -6.05 & 1.97 & -.17 & -3.06 & .002 & -9.95 & -2.16 \\
\hline Time sense ${ }^{a . b}$ & -8.20 & 3.81 & -.12 & -2.15 & .032 & -15.70 & -.70 \\
\hline Imagery amount ${ }^{\text {a.b }}$ & -7.67 & 2.89 & -.14 & -2.65 & .008 & -23.37 & -1.97 \\
\hline Internal dialogue ${ }^{a . b}$ & -8.15 & 2.97 & -.15 & -2.74 & .006 & -13.99 & -2.30 \\
\hline Rationality $^{\text {a.b }}$ & 7.84 & 2.98 & .14 & 2.62 & .009 & 1.97 & 13.71 \\
\hline Arousal $^{a . b}$ & -7.89 & 2.83 & -.15 & -2.78 & .006 & -13.47 & -2.31 \\
\hline
\end{tabular}

Linear regression analysis. a: putting gender in the model, statistical significance does not change; b: adding age to gender in the model, statistical significance is annulled.

\subsection{Relationship between Clinical Variables and Phenomenology of Consciousness}

In this study, comparing subjects with a history of PD or SM from those without these issues revealed no differences. Using linear regression analysis with each $\mathrm{PCl}$ parameter as a dependent variable, a history of PD or SM yielded no statistically significant difference.

In contrast, the sample did display differences in the phenomenology of consciousness during hypnosis, if they had a medical disease or perceived psychological trauma during the last year. In fact, as shown in Figure 4, the subjects with MD showed lower values of sexual excitement and meaning, compared to the subjects without MD. Using the linear regression analysis, we demonstrated that MD predicted these two parameters in a statistically significant manner, even when gender was added to the model as an independent variable. However, this significance was lost when age was also added to the model (Table 5).

Subjects that perceived psychological trauma during the previous year showed lower internal 
dialogue, rationality, and memory, and had higher scores for negative affect than subjects without trauma (Figure 5). The subjects with trauma were scored as 1 and subjects without trauma as 2 . Linear regression analysis indicated a positive and statistically significant relationship between trauma and memory (Table 5). This could be interpreted as a positive relationship with subjects without trauma (coded with higher scoring). This analysis remained statistically significant even when gender and age were included in the model (Table 5).

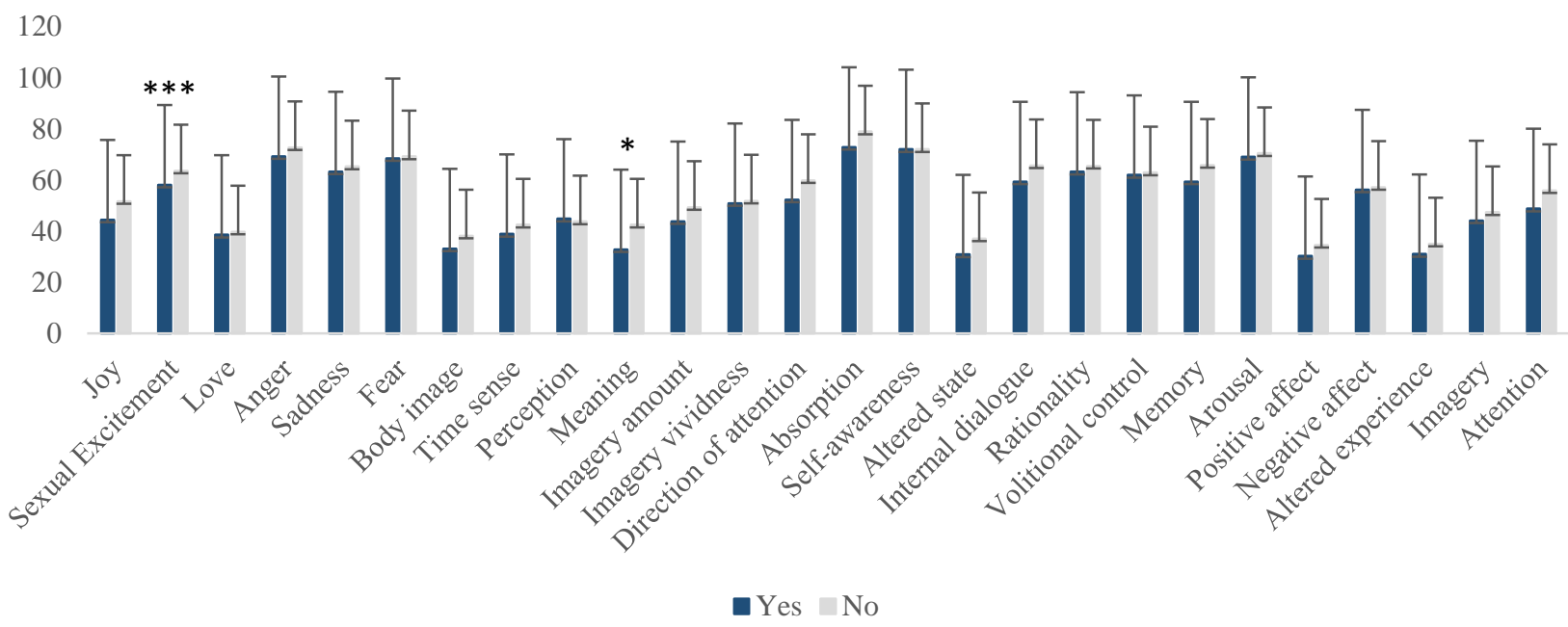

Figure 4 Differences between the subjects with and without medical disease in consciousness phenomenology (PCI) during hypnotic induction, using HGSHS:A. T-test for unpaired data analysis. ${ }^{*} p<0.05 ;{ }^{* *} p<0.01 ;{ }^{* * *} p<0.001 ;{ }^{* * * *} p<0.0001$.

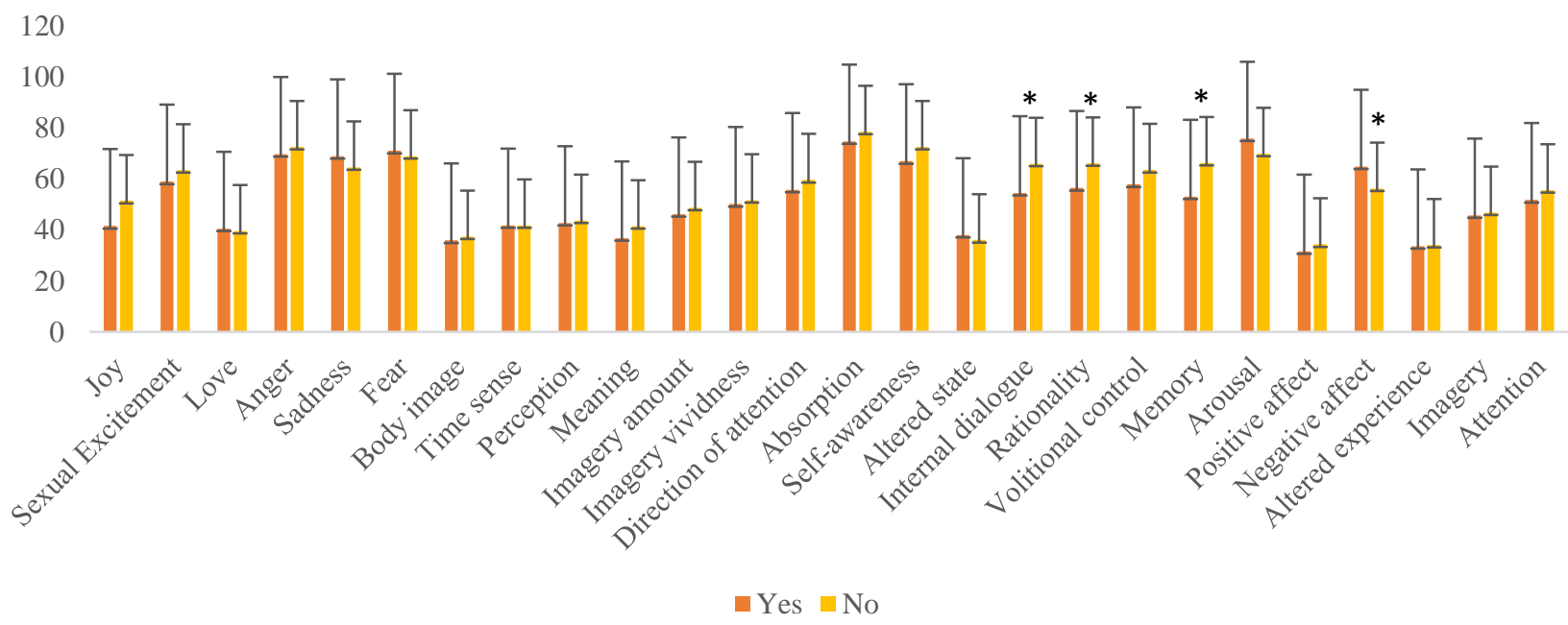

Figure 5 Difference between the subjects with and without perceived psychological trauma in consciousness phenomenology $(\mathrm{PCl})$ during hypnotic induction, using HGSHS:A. T-test for unpaired data analysis. ${ }^{*} p<0.05 ;{ }^{* *} p<0.01 ; * * * p<0.001$; $* * * * p<0.0001$. 
Table 5 Clinical variables as predictors of phenomenology of consciousness after hypnosis induction.

\begin{tabular}{|c|c|c|c|c|c|c|c|}
\hline \multirow{2}{*}{ Medical Disease } & \multirow[t]{2}{*}{ B } & \multirow[t]{2}{*}{ S.D. } & \multirow[t]{2}{*}{$\boldsymbol{\beta}$} & \multirow[t]{2}{*}{$\mathbf{t}$} & \multirow[t]{2}{*}{ Sig. } & \multicolumn{2}{|c|}{$\begin{array}{l}95 \% \mathrm{Cl} \text { for } \operatorname{Exp}(\mathrm{B}) \\
\text { Inf. Sup. }\end{array}$} \\
\hline & & & & & & & \\
\hline Sexual excitement ${ }^{a b}$ & 5.48 & 2.52 & .12 & 2.17 & .030 & .52 & 10.44 \\
\hline Meaning ${ }^{a b}$ & 9.66 & 4.29 & .12 & 2.25 & .025 & 1.22 & 18.10 \\
\hline \multicolumn{8}{|l|}{ Trauma } \\
\hline Internal dialogue ${ }^{a b}$ & 11.50 & 4.99 & .13 & 2.30 & .022 & 1.68 & 21.33 \\
\hline Memory $^{c}$ & 13.19 & 5.11 & .14 & 2.57 & .01 & 3.12 & 23.26 \\
\hline Reliability index score ${ }^{a b}$ & -.22 & .11 & -.11 & -2.06 & .040 & -.44 & -.01 \\
\hline
\end{tabular}

Linear regression analysis. a: putting gender in the model, statistical significance does not change; b: adding age to gender in the model, statistical significance is annulled. c: the statistical significant values do not change adding gender and age to the model.

\section{Discussion}

If we consider hypnosis as a "state" that is distinct from "normal" wakefulness, some assumptions should be made. Hypnosis should produce change in the experience that is not limited to specific domains of the perceptive experience, and this is associated with specific neurophysiological mechanisms for the regulation of the state of consciousness. Therefore, according to the concept of consciousness proposed by Revonsuo [28], "the science of consciousness needs to develop a phenomenological level of description that systematically captures the phenomenal level of organization in the brain". Therefore, the best way to study hypnosis is to investigate changes in the conscious state from a "phenomenology of consciousness" perspective. Deviations in the phenomenological experience from general wakeful consciousness and changes in the regulation of the states of consciousness through modification of activities of the brain systems trigger the altered state of consciousness due to hypnosis [29].

Although some individuals have a strong predisposition (as a trait) to get hypnotized, almost all people have moderate to low levels of susceptibility. Therefore, it is obvious that they will have little benefit from the therapeutic effects of hypnosis. However, research by Pekala et al. [26] introduced the possibility of recognizing individuals defined as "pseudo-low", a type of hypnotic profile that is characterized by a particular phenomenology of consciousness with a moderate level of susceptibility to hypnosis. From a clinical perspective, this evidence highlights the great subjectivity in the experience of hypnosis, and that the quality of sensation, emotion, volition, and thought (phenomenology of consciousness) plays a central role in response to suggestion.

Some research has discussed the role of context in the process of hypnosis. Subjects with a high level of hypnotizability show a "fine-grained variation" in responsiveness to suggestion. The appropriate response to suggestions could be affected by motivation, certain cognitive factors, or the hypnotic relationship [30]. On the other hand, our results indicate that the response to hypnosis may be modified by other contextual dimensions, such as sociodemographic factors or clinical conditions. Furthermore, it is now known that there are differences in the adult brain function between genders [31], and that these can change the neurophysiological mechanisms 
involved in the regulation of the conscious state during hypnosis. As we have already mentioned, previous experience of life-threatening events also changes the state of consciousness [14].

In this study, age was also observed to be a relevant factor influencing the phenomenology of consciousness during hypnosis. It negatively predicted the hypnoidal state, intended as a "general measure of trance" (i.e., decreased sensitivity or responsiveness to external stimuli, where voluntary activity becomes automatic) [17]. However, from a phenomenological perspective, considering the $\mathrm{PCl}$ parameters, greater age can actually induce a good level of hypnosis, as it also predicted greater vividness of imagery, and a reduction in time sense, fear, arousal, anger, negative affect, and perception (loss of awareness of the body's location). Greater age also contributed to a reduction in the depth of trance, negatively predicting sexual excitement, amount of imagery, altered state, altered experience, and internal dialogue, and positively predicting rationality (Table 3). On the other hand, age does not influence hypnotizability; in fact, we found no relationship between age and HGSHS:A (Figure 1), although its influence on some phenomena of consciousness could account for its negative impact on the hypnoidal state.

Our results corroborate the findings of previous research, in which females showed greater hypnotizability than males [32]. Compared to males, females had higher HGSHS:A scores, and gender was observed to be a positive predictor of hypnotizability, even after age correction (Table 2). As mentioned in the 'Results', a positive $\beta$ score in the linear regression was associated with the female gender, which was coded with the highest value ( 1 for male and 2 for female). While females were more prone to hypnosis and loss of memory of suggestions, this study showed that males tended to have an altered state of consciousness, with increased sexual excitement, positive affect, and internal dialogue (Table 4). From a neurophysiological perspective, it can be suggested that hypnosis does modify the brain's mechanism in an age- and gender-dependent fashion, and that these two demographic factors play a critical role in the altered state of consciousness associated with hypnosis.

The present results also indicate that the level of education plays a role in hypnosis, acting to decrease positive affect. In addition, although marital status may influence the modification of consciousness after hypnosis, its effect is annulled after age-correction of the model, unlike in the case of education (Table 4).

Another interesting aspect of this research was the evaluation of clinical conditions (used as context variables) such as a history of medical disease, psychiatric disorders, substance misuse, and perceived psychological trauma for the past year. Surprisingly, no differences were observed in the phenomenology of consciousness between subjects with and without psychiatric disorders or substance misuse. However, there were differences between subjects who reported medical disease or psychological trauma during the past year. Specifically, subjects with the medical disease showed lower levels of sexual excitement and meaning after hypnosis, compared to subjects without (Figure 4). Furthermore, the medical disease also appeared to predict reduction in sexual excitement and meaning (with MD coded " 1 "; without MD coded " 2 "). Correction for gender did not alter these results, but adding age to the model annulled the statistically significant regression for both the parameters (Table 5).

In contrast, subjects with perceived psychological trauma during the preceding year showed lower levels of internal dialogue, rationality, and memory of suggestions, as well as an increased level of negative affect, compared to subjects without perceived trauma (Figure 5). The perception of trauma proved to be a negative predictor (trauma coded " 1 "; no trauma coded " 2 ") of internal 
dialogue and memory (Table 5). However, when gender and age were added to the linear regression model, the prediction was only confirmed for $\mathrm{PCl}$ memory (Table 5).

This study has some limitations. In particular, it would have been preferable to administer a questionnaire on the phenomenology of consciousness before inducing hypnosis, in order to pinpoint the variations in consciousness induced by suggestion (i.e., suggesting two min of silence without hypnotic induction). It might also have been more enlightening to explore clinical variables in further detail, using specific instruments. Furthermore, dividing patients into specific age groups could have enabled better exploration of the age-related changes. Considering these limitations, it would, therefore, be desirable to explore these aspects in a future study using a larger sample.

\section{Conclusion}

The results of this research confirm the subjective experience of hypnosis. Besides the degree of hypnotizability, several other factors can affect the change in subjective experience induced by suggestion. "The mental ease, absorption, reduction of self-orientation, and automaticity that characterized the altered state of consciousness of hypnosis" [29] is, therefore, the result of a combination of several individual predisposing traits with some contextual variables in a specific situation. These results demonstrate the influence of age and gender in hypnosis. Specifically, gender affects the level of hypnotizability, while age affects the depth of trance. Both factors also affect the phenomenology of consciousness, with age playing a critical role in reducing negative emotions, perception, and arousal, and increasing temporal distortion and vividness of imagery, while gender reduces the memory of suggestions in females, and increases dissociative phenomena and body perception in males.

Reduced memory of suggestions was also found to be associated with perceived psychological trauma, corroborating the findings of previous research that correlated trauma with a change in the state of consciousness. Memory could represent the cognitive area that is primarily affected by the experience of trauma, and from the perspective of clinical application [33], could represent a gateway to trance for hypnotic induction in these subjects.

In summary, this retrospective study highlights how important it is to consider contextual variables that, although limited to sociodemographic factors, might also include clinical conditions which are yet to be thoroughly investigated from this perspective.

\section{Acknowledgments}

Thanks to Anna Forster for English editing assistance and Ronald Pekala and Vilfredo De Pascalis for all material and articles sent to me.

\section{Author Contributions}

Antonella Ciaramella is the sole author who conceived, carried out and wrote this study.

\section{Competing Interests}

The authors declare that no competing interests exist. 


\section{References}

1. Vithoulkas G, Muresanu DF. Conscience and consciousness: A definition. J Med Life. 2014; 7: 104-108.

2. De Sousa A. Towards an integrative theory of consciousness: Part 1 (neurobiological and cognitive models). Mens Sana Monogr. 2013; 11: 100-150.

3. Pekala RJ. Hypnosis as a "state of consciousness": How quantifying the mind can help us better understand hypnosis. Am J Clin Hypn. 2015; 57: 402-424.

4. Brown DP, Fromm E. Hypnotherapy and hypnoanalysis. Routledge; 2013.

5. Holroyd J. The science of meditation and the state of hypnosis. Am J Clin Hypn. 2003; 46: 109128.

6. Weitzenhoffer AM. Scales, scales and more scales. Am J Clin Hypn. 2002; 44: 209-219.

7. Weitzenhoffer AM. The practice of hypnotism, Vol. 1: Traditional and semi-traditional techniques and phenomenology; Vol. 2: Applications of traditional and semi-traditional hypnotism. Non-traditional hypnotism: John Wiley \& Sons; 1989.

8. Pellicer Asensio X, Fusté Escolano A, Ruiz Rodríguez J. Psychometric analysis of the Barber Suggestibility Scale in a clinical population. Am J Clin Hypn. 2018; 60: 386-402.

9. Brugnoli MP, Pesce G, Pasin E, Basile MF, Tamburin S, Polati E. The role of clinical hypnosis and self-hypnosis to relief pain and anxiety in severe chronic diseases in palliative care: A 2year long-term follow-up of treatment in a nonrandomized clinical trial. Ann Palliat Med. 2018; 7: 17-31.

10. Green JP, Lynn SJ, Montgomery GH. Gender-related differences in hypnosis-based treatments for smoking: A follow-up meta-analysis. Am J Clin Hypn. 2008; 50: 259-271.

11. Cahill L. Why sex matters for neuroscience. Nat Rev Neurosci. 2006; 7: 477-484.

12. Zhong YH, Wu HY, He RH, Zheng BE, Fan JZ. Sex differences in sex hormone profiles and prediction of consciousness recovery after severe traumatic brain injury. Front Endocrinol. 2019; 10: 61.

13. Rainville P, Hofbauer RK, Bushnell MC, Duncan GH, Price DD. Hypnosis modulates activity in brain structures involved in the regulation of consciousness. J Cogn Neurosci. 2002; 14: 887-901.

14. Bækkelund H, Frewen P, Lanius R, Ottesen Berg A, Arnevik EA. Trauma-related altered states of consciousness in post-traumatic stress disorder patients with or without comorbid dissociative disorders. Eur J Psychotraumatol. 2018; 9: 1544025.

15. Ciaramella $A$. The influence of trauma on autobiographical memory in the assessment of somatoform disorders according to DSM IV criteria. Psychiatr Q. 2018; 89: 991-1005.

16. Pekala RJ. The phenomenology of consciousness inventory. In: Quantifying consciousness. Springer; 1991. p. 127-143.

17. Pekala RJ, Baglio F, Cabinio M, Lipari S, Baglio G, Mendozzi L, et al. Hypnotism as a function of trance state effects, expectancy, and suggestibility: An Italian replication. International Int J Clin Exp Hypn. 2017; 65: 210-240.

18. Shor RE, Orne EC. Harvard group scale of hypnotic susceptibility, form A. Palo Alto, CA: Consulting Psychologists Press; 1962.

19. De Pascalis VD, Russo P, Marucci FS. Italian norms for the Harvard Group scale of hypnotic susceptibility, form A. Int J Clin Exp Hypn. 2000; 48: 44-55. 
20. Weitzenhoffer AM, Hilgard ER. Stanford hypnotic susceptibility scale, form C. Palo Alto, CA: Consulting Psychologists Press; 1962.

21. Hand J, Pekala RJ, Kumar V. Prediction of Harvard and Stanford Scale scores with a phenomenological instrument. Austral J Clin Exper Hypn. 1995; 23: 124-124.

22. Elkins GR, Barabasz AF, Council JR, Spiegel D. Advancing research and practice: The revised APA Division 30 definition of hypnosis. Int J Clin Exp Hypn. 2015; 63: 1-9.

23. Wagstaff GF, Cole JC, Brunas-Wagstaff J. Measuring hypnotizability: The case for self-report depth scales and normative data for the Long Stanford Scale. Int J Clin Exp Hypn. 2008; 56: 119-142.

24. Ceunen E, Vlaeyen JW, Van Diest I. On the origin of interoception. Front Psychol. 2016; 7: 743.

25. Kumar V, Pekala RJ, Cummingsu J. Trait factors, state effects, and hypnotizability. Int J Clin Exp Hypn. 1996; 44: 232-249.

26. Pekala RJ. A short unobtrusive hypnotic induction for assessing hypnotizability level: I. Development and research. Am J Clin Hypn. 1995; 37: 271-283.

27. Weitzenhoffer AM, Hilgard ER, Cooper LM, Lauer LW, Morgan AH. Stanford hypnotic susceptibility scale: Forms $A$ and $B$, for use in research investigations in the field of hypnotic phenomena. Palo Alto, Calif: Consulting Psychologists Press; 1959.

28. Revonsuo A. Prospects for a scientific research program on consciousness. Neural correlates of consciousness: Empirical and conceptual questions. Cambridge, MA: MIT Press; 2000. p. 57-75.

29. Rainville $P$, Price DD. Hypnosis phenomenology and the neurobiology of consciousness. Int J Clin Exp Hypn. 2003; 51: 105-129.

30. Sheehan PW. Hypnosis, context, and commitment. Guilford Press; 1991. p. 57-75.

31. Ritchie SJ, Cox SR, Shen X, Lombardo MV, Reus LM, Alloza C, et al. Sex differences in the adult human brain: Evidence from 5216 UK biobank participants. Cerebral Cortex. 2018; 28: 2959-2975.

32. Költő A, Gősi-Greguss AC, Varga K, Bányai Él. The influence of time and gender on hungarian hypnotizability scores 1. Int J Clin Exp Hypn. 2014; 62: 84-110.

33. Erickson MH. Further clinical techniques of hypnosis: Utilization techniques. Am J Clin Hypn. 1959; 2: 3-21.

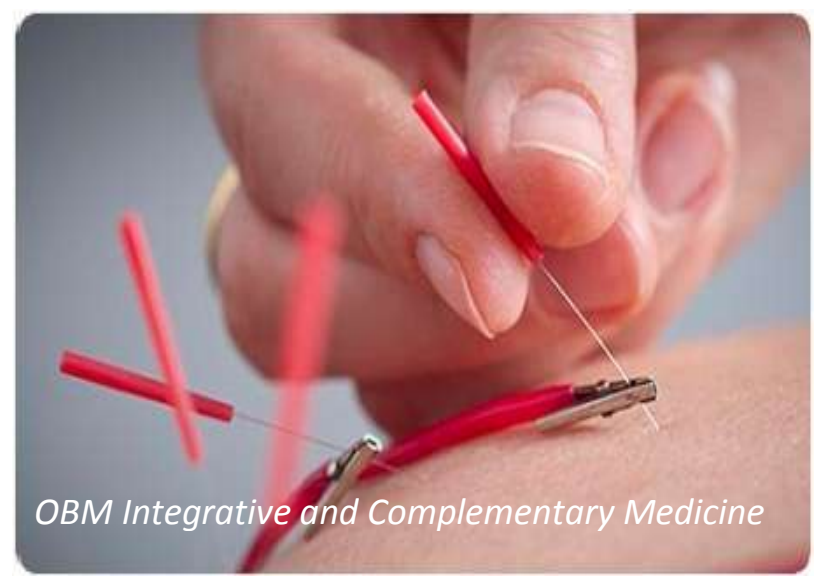

Enjoy OBM Integrative and Complementary Medicine by:

1. Submitting a manuscript

2. Joining in volunteer reviewer bank

3. Joining Editorial Board

4. Guest editing a special issue

For more details, please visit: http://www.lidsen.com/journals/icm 